\title{
Enseñanza del Derecho Animal en España*
}

Keywords: derecho animal; España; enseñanza

Las cuestiones que deseo plantear en este editorial, de forma breve y sucinta, son las siguientes:

1. Qué es el Derecho Animal

2. Por qué enseñar Derecho Animal

3. Para qué sirve enseñar el Derecho Animal

4. Qué elementos componen el Derecho Animal

\section{Qué es el Derecho Animal}

El Derecho Animal es una rama emergente del Derecho, relativamente nueva en España, pero con un reconocimiento y una ya larga tradición académica en los Estados Unidos de América.

El Derecho Animal, como toda disciplina jurídica, aborda las relaciones de conflicto (potencial o real) dentro de una sociedad organizada. En este caso, entre humanos y animales, desde la perspectiva de las diferentes disciplinas que confluyen en la finalidad de regular, de forma ajustada a Derecho, los intereses de los animales y los intereses y responsabilidades de los seres humanos con respecto a aquéllos.

El Derecho Animal es una disciplina jurídica transversal e internacional que si bien se formula de forma autónoma, en interdependencia con otras materias jurídicas consolidadas, ha experimentado el influjo de una sociedad global y de los nuevos avances científicos en el campo del Bienestar Animal.

La Ciencia del Bienestar Animal, ha cumplido acabadamente -durante muchos años- el papel de investigar las necesidades de los Animales como "seres sintientes", expresión ésta procedente del mundo de la Ciencias relativas a los Animales y el medio ambiente, que se ha integrado dentro del mundo jurídico como expresión del grado de tratamiento y protección de los Animales, que el sistema jurídico ya ha hecho suya.

Hoy en día, tanto en el campo científico como en el jurídico y social, la expresión "sentient beings" constituye tanto una frontera para rechazar y castigar aquellas prácticas que constituyen maltrato animal, como el punto de partida para construir recursos jurídicos y políticas públicas de protección de los intereses de los animales dentro del medio que les es propio, por lo que, la extensión de esta protección al entorno donde la mayoría de los Animales viven, que se suele reconocer como protección de la Biodiversidad, resultan intereses concurrentes.

En consecuencia, cuando pensamos en seres sentientes, la ciencia del Bienestar Animal no excluye a ningún animal, como tampoco deberían excluirlos las Ciencias Jurídicas. La sentiencia animal y el reconocimiento de su protección está en relación, la mayoría de las veces, con el rendimiento económico que de los animales se obtiene, pero el respeto por los animales y por sus intereses -lo que constituye el núcleo del Derecho Animal-, no tiene, de entrada, límites por el tamaño, la belleza, el uso que se les dé, o por la proximidad mayor o menor con nuestra vida cotidiana. Otra cuestión es cómo debería articularse 
hoy en día ese triple aspecto:

a) el respeto social por los animales y su regulación en conflictos entre particulares

b) las políticas públicas para hacer efectivo dicho respeto

c) la protección jurídica de los animales como seres sentientes, capaces de experimentar dolor y placer, miedo o estrés.

Precisamente, estas son las grandes áreas de interés primario del Derecho Animal:

a) la cuestión de la propiedad sobre los animales y su evolución reciente

b) la cuestión de la legislación "anti-crueldad" contra los animales y su extensión a todo tipo de animales

c) la aplicación de las reglas del Bienestar Animal, a todos los animales sin exclusión

\section{Por qué enseñar Derecho Animal}

La enseñanza del Derecho Animal, en las Facultades jurídicas es una necesidad que la sociedad demanda y de forma mas clara en España a lo largo de la última década, pues abre las puertas al ejercicio de profesiones jurídicas relacionadas con los animales, en una nueva dimensión más conforme a las necesidades de una sociedad que exige un espacio jurídico explícito para los animales y sus relaciones con los seres humanos.

La discusión de la situación jurídica de los animales en el Derecho, es a menudo infravalorada en el ámbito jurídico. Sin embargo, hay una abundantísima literatura específica, tanto en el mundo angloamericano como europeo sobre aspectos que son centrales para explicar los cambios operados en el estatuto jurídico de los animales. En el derecho continental (Civil Law), hay que hacer especial referencia a los Códigos Civiles de Alemania (BGB), de Austria ( ABGB) y de Suiza, en la década comprendida entre finales de los 80' y 90', que cambiaron el estatus de los animales, que pasaron de ser considerados un simple objeto (una "cosa" o res) a una categoría especial entre el ser humano y las cosas, cuya denominación fue la de "no cosas". Esta categoría, representó, sin duda, un gran avance, pero pecó de falta de ambición y de carencia de técnica jurídica. Como es bien sabido, es una categoría que está en crisis, por resultar, sencillamente, inaplicable. Desde este punto de vista es muy importante discernir si el animal es tratado como un simple objeto en la legislación o puede tener un estatus propio y diferenciado, como recientemente le ha otorgado Francia en el Code civil.

De dicha actualización no se seguirían sólo beneficios para los animales, sino para la ciencia jurídica, que abriría una nueva frontera de debate, con repercusiones para la sociedad en su conjunto y para la solución de algunos problemas concretos que las Ciencias del Bienestar Animal han tratado de resolver, como, p.e., la situación de los animales de granja, de compañía o de espectáculos, que siguen esperando, no obstante, una solución a nivel global. Por ello, a día de hoy, se producen paradojas como que, dentro de la sociedad, el animal no se considera como un simple objeto. Es decir, se admite que a menudo son vistos como miembros en una familia, la carne de los animales se come pero la preocupación de cómo se ha producido todavía no constituye una cuestión de interés prioritario para el consumidor medio. Pensamos que reconocer un nuevo estatuto jurídico de los animales en el Derecho, puede llevar a una mejor comprensión de la propia sociedad en la que vivimos y a una mejora de las relaciones entre humanos y animales.

\section{Para qué sirve enseñar el Derecho Animal}

El papel que los animales desempeñan en la sociedad ha sido cambiante. En estos momentos, puede afirmarse que, tras siglos de silencio por parte del Derecho, los animales están abriéndose camino en el campo del Derecho. Prueba de ello son las muchas sentencias que emiten los Tribunales de nuestro país, en contraste con la práctica inexistencia de Jurisprudencia animal hasta hace sólo muy pocos años. 
Los retos que una enseñanza reglada del Derecho Animal, facilitaría alcanzar, pueden formularse del siguiente modo:

a) Desde el punto de vista estrictamente jurídico, se podría esperar de la aplicación de la sentiencia de los animales, una mejora de la legislación tanto constitucional, civil como administrativa y penal muy significativa. Son varios los textos programáticos de la UE que vienen, desde hace 40 años, reconociendo la sentiencia animal como guía de la legislación de Bienestar animal, pero no ha sido hasta el 2009, en el art. 13 del TFUE, llamado Tratado de Lisboa, donde se impone a los Estados Miembros la obligación de tratar a los animales como "seres sintientes" en la legislación interna de cada uno de los Estados Miembros, particularmente en materia de agricultura, ganadería, experimentación y espectáculos. Bien sabido es que las excepciones, explícitamente mencionadas en el párrafo segundo del citado art. 13 TFUE (ritos religiosos, costumbres regionales tradiciones culturales), han dejado muy debilitado el mencionado artículo 13 y sus posibles aplicaciones, singularmente, en el caso de España y Francia, en tema de espectáculos taurinos.

b) Desde el punto de vista social, la promoción de una conciencia ciudadana informada y objetiva. Ello demanda la adaptación de los usos, que caracterizan a una sociedad que ha integrado a los animales como seres dignos de respeto, dentro de la vida diaria: transportes, alojamiento, vacunación, identificación, consumo (información, etiquetaje, responsabilidad), educación en el respeto en todos los niveles de enseñanza, turismo responsable, relación humano-animal desde la perspectiva de la tenencia responsable y la promoción de vínculos estables, la manipulación de los animales, la definición de las necesidades de bienestar físico y comportamentales de los animales, las condiciones y límites del estudio de los animales y de los tests que se puedan realizar (por cierto, Nueva Zelanda prohibió recientemente los tests con animales para la industria cosmética y así mismo, la venta de productos cosméticos testados con animales, lo que ya se había hecho en la UE desde 2009), la obligación de aliviar el dolor, el estrés, el miedo y la enfermedad de los animales, establecer penas graves para los casos de abuso y maltrato de animales y la violencia contra ellos y contra los elementos más vulnerables de la sociedad, niños especialmente.

c) Desde el punto de vista de la agenda pública, la implementación de las políticas tendentes a proteger el interés del animal de no ser maltratado -lo que hoy es un postulado reconocido por la ciencia del Bienestar Animal- , con el mismo nivel de interés que tiene el titular de la propiedad de proteger su derecho. Las cuestiones de bienestar animal deben alcanzar el estatus de una responsabilidad del Estado, suficientemente importante y claramente definida, de forma que se regule la del dueño del animal. La opción en algunos Estados europeos ha sido mediante el reconocimiento del bienestar animal como un deber del Estado en la propia Constitución, para la creación de un equilibrio entre los intereses del titular de un lado y del animal por el otro.

\section{Qué elementos componen el Derecho Animal}

Los estudios sobre Animales, se han enriquecido en las últimas décadas con la proyección de los intereses de aquéllos dentro del mundo jurídico, lo que está rompiendo el tradicional silencio del Derecho respecto de los Animales -que ha caracterizado estos estudios-, prácticamente desde la Antigüedad Clásica hasta épocas muy recientes.

El Derecho Animal es una especialidad transversal del Derecho, a cuya formación y desarrollo contribuyen disciplinas aparentemente alejadas tradicionalmente del diálogo científico conjunto, pero que comparten el mismo interés y sujeto de atención, que son los animales en el seno de una sociedad globalizada. Me refiero, por tanto:

a) a las disciplinas jurídicas más tradicionalmente relacionadas con los animales (Civil, Penal, Mercantil, Internacional, Procesal, Administrativo), la legislación especializada (estatal, autonómica, local, de la UE e internacional) y la Jurisprudencia relativa, que en los últimos años ha experimentado un crecimiento y profundidad muy notables; 
b) así como aquéllas materias de afinidades concomitantes a los animales, como las ciencias veterinarias, la ética, la economía, la nutrición, las ciencias medioambientales, las ciencias de la salud y las humanidades.

Se trata de promover un verdadero ejercicio de cooperación intelectual, que en relación a los animales -aunque hoy parezca haberse olvidado-, se lleva a cabo desde la Antigüedad. Pero de este aspecto trataré en otra ocasión. Bien es cierto, que la confluencia de los intereses de las ciencias implicadas en la consecución de un objetivo constituye un fenómeno "natural". En el sentido de que las ciencias, cuando lo son, no son minúsculos espacios de conocimiento encerrados en sí mismos, sino, muy al contrario, tienden a la especialización abierta y a la cooperación entre profesionales que puedan aportar sus conocimientos para reforzar y avanzar en los propios hallazgos.

Esta es una de las grandezas y de las dificultades del Derecho Animal. Lo que señala su singularidad y, al mismo tiempo, su justificación como disciplina autónoma del Derecho. El tratamiento de los animales se contempla a día de hoy como un espacio holístico de estudio y acción, para el que se requiere de una verdadera cooperación científica organizada.

Que el Derecho Animal sea reconocido como una rama más del Derecho en todas las Facultades de Derecho de España, sería un avance muy deseable. Nuestra mira está puesta en los animales, en saber más para trabajar mejor por ellos.

Palabras clave: Enseñanza del Derecho Animal, Ciencia del Bienestar Animal, seres sintientes, art. 13 TFUE

LA EDITORA

Teresa Giménez-Candela

Catedrática de Derecho Romano

Directora del Master en Derecho Animal y Sociedad

Directora del SGR Grupo de Investigación ADS

Universitat Autònoma de Barcelona

Sígueme en Facebook: https://www.facebook.com/editora.da

\begin{abstract}
* La idea de publicar estas reflexiones (deliberadamente sintéticas), deriva de mi propia experiencia docente en Derecho Animal desde el curso 2007-2008, a través de la asignatura "Derecho y Bienestar Animal", que figura en el plan de estudios oficial de la Facultad de Derecho de la Universidad Autònoma de Barcelona, como asignatura optativa del segundo ciclo. Son ya varias generaciones de futuros abogados que se ocuparán en el desempeño de su oficio -o no-, de casos relativos a animales, pero lo que es seguro es que tienen un criterio propio y una formación sólida acerca del trato que un Estado de Derecho les debe y les debería procurar a los animales.
\end{abstract}

Estas reflexiones nacen del estudio y de la experiencia de hace muchos años, que se han hecho más visibles en la última década. En este sentido, soy la creadora y directora del Máster en Derecho Animal y Sociedad, que este año ha comenzado su $\underline{5}$ a edición presencial, así como del Máster on line en Derecho Animal y Sociedad, que se realiza en colaboración con la prestigiosa editorial jurídica Tirant lo Blanch. He fundado y edito la página web derechoanimal.info, que ya ha alcanzado 5 años de experiencia, como vehículo para difundir de forma abierta los avances que el Derecho Animal está experimentando en el mundo, así como para ofrecer la única base de datos, de Legislación y Jurisprudencia en Derecho Animal, con más de 30.000 entradas de ámbito tanto estatal, autonómico, local, UE e internacional. Desde 2007 dirijo el SGR Grupo de Investigación (Animales, Derecho y Sociedad), que es un verdadero "Think-Tank", interdisciplinar e internacional, desde el que elaboramos trabajos de investigación (tesis doctorales, dictámenes, TFM, TFG), proyectos de investigación, organización de congresos, conferencias, workshops, cursos monográficos, así como publicaciones en revistas de contrastado valor científico. He promovido y dirijo la Colección jurídica "Animales y Derecho" y la Colección de E-Books "Biblioteca del Máster en Derecho Animal" (de pronta aparición), ambas en la editorial jurídica "Tirant lo Blanch". 